Background: Systemic AA amyloidosis is a serious and life-threatening complication of chronic inflammatory diseases such as rheumatoid arthritis, spondyloarthritis (SpA), and periodic fever syndromes. While most common cause of AA amyloidosis is Familial Mediterranean Fever; Ankylosing Spondylitis (AS) is another frequent cause of AA amyloidosis in Turkey.

Objectives: We aimed to evaluate the response of secukinumab (SEC) treatment in three patients with AS and AA amyloidosis (AS-AA) in our tertiary referral centre.

Methods: We retrospectively evaluated three AA amyloidosis patients who fulfilled Modified New York Criteria for diagnosis of AS in our AA amyloidosis cohort with 163 patients. Diagnosis of AA amyloidosis was confirmed by Congo red stain and by monoclonal AA-specific antibodies.

Results: Patient 1: 61-year-old male patient with inflammatory back pain (IBP) and peripheral arthritis for 14 years was evaluated in our clinic. After methotrexate (MTX) failure, he used adalimumab (ADA), etanercept (ETA) and certolizumab (CZP). Nephrotic range proteinuria was detected when he was on CZP, and rectum biopsy documented AA amyloidosis 3 years ago. After the diagnosis, CZP treatment was switched to infliximab (IFX). IFX was ineffective in controlling inflammatory findings. SEC was started 15 months ago and he responded partially. The dose of SEC was increased to $300 \mathrm{mg}$ monthly, which resulted in a sustained improvement in clinical and laboratory findings.

Patient 2: 69-year-old woman was admitted to our clinic with peripheral arthritis in addition to the history of IBP for 19 years in 2005. MTX, NSAID and prednisolone were started. Because of inefficacy to conventional treatments and development of nephrotic range proteinuria, ETA was added to treatment. The patient responded to ETA and was followed-up for 13 years without symptoms of $A S$ and proteinuria. ETA was switched to IFX due to secondary inefficacy two years ago. On the third month of IFX treatment, she developed demyelinating polyneuropathy. IFX treatment was switched to SEC and she is still being followed-up on SEC without any findings of AS and proteinuria.

Patient 3: 49-year-old woman who was on sulphasalasine for 24 years for treatment of ulcerative colitis (UC) was evaluated for recent onset IBP and peripheral arthritis in 2007. After failure of MTX, she started to receive IFX. She did not respond to first IFX and then ADA and CZP, and she developed nephrotic range proteinuria when she was on anti-TNF. Her serum creatinine increased progressively, and haemodialysis $(H / D)$ was started six months later. Due to ongoing IBP and elevated acute phase response with CZP treatment, SEC was started. Significant improvement was observed in both clinical and laboratory findings with no worsening of UC.

Table 1. Clinical characteristics, laboratory findings and treatment responses of patients

\begin{tabular}{|c|c|c|c|}
\hline & Patient 1 & Patient 2 & Patient 3 \\
\hline Age (year) & 61 & 69 & 49 \\
\hline Sex & Male & Female & Female \\
\hline Age of AS onset (year) & 47 & 35 & 25 \\
\hline Age of amyloidosis diagnosis (year) & 57 & 50 & 46 \\
\hline Amyloidosis duration (months) & 42 & 168 & 30 \\
\hline Family history & No & AS and amyloidosis in siblings & No \\
\hline HLA-B 27 status & Positive & Positive & Not available \\
\hline MEFV status & Negative & Negative & $\begin{array}{l}\text { M694V hete- } \\
\text { rozygous }\end{array}$ \\
\hline Organ involvement of amyloidosis & $\begin{array}{l}\text { GIS and } \\
\text { kidney }\end{array}$ & $\begin{array}{c}\text { Kidney, liver, heart, bone } \\
\text { marrow }\end{array}$ & GIS, kidney \\
\hline $\begin{array}{l}\text { Secukinumab duration (months) } \\
\quad \text { CRP (mg/L) }\end{array}$ & 15 & 18 & 24 \\
\hline Before & 27 & 15 & 23 \\
\hline After & 2.4 & 4.5 & 2.8 \\
\hline \multicolumn{4}{|l|}{ Creatinine $(\mathrm{mg} / \mathrm{dl})$} \\
\hline Before & 0.5 & 1.6 & $H / D$ \\
\hline After & 0.5 & 1.3 & $H / D$ \\
\hline \multicolumn{4}{|l|}{ Proteinuria (g/day) } \\
\hline Before & 4.2 & 5.5 & $H / D$ \\
\hline After & 2.4 & 0.9 & $H / D$ \\
\hline \multicolumn{4}{|l|}{ Albumin (g/dL) } \\
\hline Before & 2.7 & 2.5 & 3.1 \\
\hline After & 3.1 & 4.3 & 4.2 \\
\hline \multicolumn{4}{|l|}{ ASDAS } \\
\hline Before & 4.1 & 1.6 & 4.6 \\
\hline After & 1.8 & 1.1 & 1.7 \\
\hline
\end{tabular}

GIS: Gastrointestinal System, ASDAS: Ankylosing Spondylitis Disease Activity Score

Conclusion: AA amyloidosis is a rare complication of SpA, and SEC treatment was found to be safe and effective in our three patients with AS-AA. Although anti-TNF agents have previously used successfully in treatment of AS-AA, SEC may be a new option especially in patients who are resistant or intolerant to anti-TNFs.
Disclosure of Interests: None declared

DOI: 10.1136/annrheumdis-2021-eular.1469

\section{AB0767 SEVERE BREAST ULCERATION IN BEHÇET'S DISEASE TREATED WITH CYCLOPHOSPHAMIDE: A CASE REPORT}

E. Ball ${ }^{1}$, D. Okane ${ }^{2}$, C. Mccourt ${ }^{2}$, M. Mccarron ${ }^{1}$, C. Riddell ${ }^{1} .{ }^{1}$ Belfast City Hospital, Rheumatology, Belfast, United Kingdom; ${ }^{2}$ Belfast City Hospital, Dermatology, Belfast, United Kingdom

Background: Behcet's disease is a systemic autoimmune vasculitis that typically involves mucocutaneous surfaces, the eyes and the skin with varying manifestations. Skin ulceration often secondary to pathergy is a common feature.

Objectives: To raise awareness of breast ulceration as a clinical manifestation in Behcet's disease.

Methods: We report a case of complex Bechet's disease associated with severe refractory breast ulceration successfully treated with cyclophosphamide.

Results: A 27 year old female patient presented to the rheumatology department with a non-healing lesion on her face secondary to a cat scratch. She reported previous episodes of ulceration usually as a result of minor trauma such as IV cannulation, as well as a two year history of severe oral and genital ulceration. She had also been diagnosed with 'colitis' requiring iliocaecal resection two years prior to presentation. Previous treatments for her bowel included azathioprine, infliximab, adalimumab and vedolizumab. Over the next three years she developed recurrent eye involvement in the form of scleritis with ongoing oral and genital ulceration. Further treatment under our care included ustekinumab, entanercept, benepali, certolizumab and tacrolimus with background prednisolone. She then developed a small area of broken skin on her left breas which continued to extend and ulcerate despite treatment with IV steroids. Tissue biopsy showed deep focal vasculitis with intravascular thrombi. Anticoagulation was commenced and she was treated with tocilizumab IV for 3 months with no clinical improvement. Involvement extended to include 80 percent of the breas surface and the nipple self-amputated. Due to the severity and extent of the ulceration which was extremely painful and distressing, she was given 3 months of IV cyclophosphamide at a dose of $15 \mathrm{mg} / \mathrm{kg}$ every $2-3$ weeks. The ulceration showed rapid clinical improvement (see Figure 1).

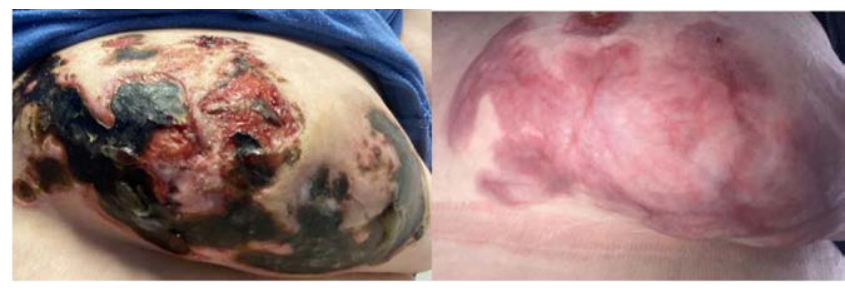

Figure 1. Breast ulceration before and after 3 months of cyclophosphamide treatment

Conclusion: Involvement of the breast in systemic vasculitides (such as GPA or PAN) has been reported, although usually manifesting as a palpable mass with diagnosis on biopsy ${ }^{1}$. Similar presentations in Behcet's disease have been recognised ${ }^{2}$, although much less commonly. Our case demonstrates that severe breast ulceration can be a clinical manifestation of this condition and can be refractory to usual therapies.

\section{REFERENCES:}

[1] Ren J, Liu J, Su J, Zhang J, Zhao J. Systemic vasculitis involving the breast a case report and literature review. Rheumatol Int. 2019 Aug;39(8):1447-1455

[2] Soleto MJ, Marcos L. Behçet's disease involving the breast. Eur Radiol. 2002 Dec;12 Suppl 3:S98-S100. doi: 10.1007/s00330-002-1420-4.

Disclosure of Interests: None declared

DOI: 10.1136/annrheumdis-2021-eular.1639

AB0768

\section{NEUROLOGICAL MANIFESTATIONS IN} GRANULOMATOSIS WITH POLYANGIITIS: ABOUT 11 CASES

O. Jomaa ${ }^{1}$, O. Berriche ${ }^{1}$, S. Arfa ${ }^{1}$, A. Fraj $^{1}$, M. Belkhiri ${ }^{1}$, R. Makhloufi ${ }^{1}$,

W. Romdhane ${ }^{1}$, M. Hermassi ${ }^{1} .{ }^{1}$ University Hospital Tahar Sfar Mahdia, Tunisia, Internal Medicine Department, Mahdia, Tunisia

Background: Granulomatosis with polyangiitis (GPA) is a rare systemic vasculitis, affecting mainly the superior airways, lungs and kidneys. Neurological impairment is frequent, described in 22 to $54 \%$ of cases, and rarely inaugurates the disease. 